\title{
Renal Glucosuria-Most Frequent Condition with Positive Urine Glucose in A Screening Program at School
}

\author{
Junichi Suzuki and Tatsuhiko Urakami* \\ Department of Pediatrics, Nihon University School of Medicine, Japan
}

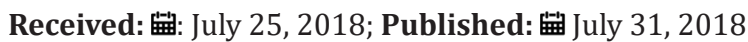

*Corresponding author: Tatsuhiko Urakami, Department of Pediatrics, Nihon University School of Medicine, 1-6 Kandasurugadai Chiyoda-ku, Tokyo 101-8309, Japan

Abbreviations: RG: Renal glucosuria; OGTT: Oral Glucose Tolerance Test; PG: Plasma Glucose; SGLT: Sodium/Glucose Cotransporter

\section{Mini Review}

Renal glucosuria (RG) is a disorder of proximal tubular glucose transport, characterized by abnormal urinary excretion of glucose in the absence of impaired glucose metabolism. In some affected families, RG is caused by homozygosity or compound heterozygosity of mutations in the SCL5A2 gene, encoding the renal-specific sodium/glucose cotransporter 2. Some children are detected as urine glucose positive with no evidence of hyperglycemia in a screening program at school, and are diagnosed as having RG. We found about $30 \%$ of Japanese school students with a positive result at a urine glucose screening program at school was diagnosed with diabetes. On the other hand, the others, almost $70 \%$ of cases, with positive urine glucose was finally identified as having RG with no evidence of glucose intolerance in the detailed examination. They had a strong family history of RG. We conclude that RG may be not rare, but a frequent condition with glucosuria among Japanese school children.

Marble [1] defined clinical diagnostic criteria in RG, and the condition was revealed to be autosomal recessive and uncommon. These criteria included normal plasma glucose (PG) level on oral glucose tolerance test (OGTT), normal plasma levels of insulin and glycosylated hemoglobin (HbA1c), and relative stable urinary excretion of glucose (10-100 g/day) in all urine specimen Lawrence [2] later proposed another criterion as normal glucose tolerance on OGTT, regardless of the presence of glucosuria in the fasting state. Cases fulfilling Marble's criteria appear to be few, whereas, Desjeux [3] reported that about $60 \%$ of subjects with positive urine glucose were diagnosed as having RG based on the criteria proposed by Lawrence. In some affected families, RG is caused by homozygosity or compound heterozygosity of mutations in the SCL5A2 gene, encoding the renal-specific sodium/glucose cotransporter (SGLT) 2
[4-6]. SGLT2 is known to be the principal transporter that mediates glucose resorption [7].

Two major forms of SGLT, SGLT1 and SGLT2, are independently expressed in the renal proximal tubular cells and they are shown to be responsible for glucose reabsorption from glomerular filtrate. SGLT1 is predominantly expressed in enterocytes, with the major function of active glucose and galactose transport. Although not involved in resorption of the bulk of glucose in the kidney, the characteristics of SGLT1 are favorable for glucose transport when present at low concentrations. On the other hand, SGLT2 is predominantly expressed in the luminal brush border of the proximal tubule and is responsible for the vast majority of glucose reabsorption from glomerular filtrate [8]. Familial RG is known to be caused by mutations in the SCL5A2 gene, encoding SGLT2, and is classified into 3 types according to urinary excretion of glucose levels. Subjects with type A RG are characterized by a low renal threshold for glucose and a low maximum tubular glucose reabsorption. Those with type B show a low threshold but exhibit normal maximum tubular glucose reabsorption. On the other hand, subjects with type 0 show complete absence of renal glucose transport [8]. Individuals with homozygous mutations in the SCL5A2 gene exhibit persistent heavy glucosuria and are designated as type 0 , whereas those with heterozygous mutations show mild or trait glucosuria [9].

Some children, detected as urine glucose positive with no evidence of hyperglycemia in a screening program at schools, are identified as having RG [10]. We have conducted a urine glucose screening program, concomitant with screening for hematuria and proteinuria, using morning urine specimens from primary and junior high 
school children, residing at the Tokyo Metropolitan Area since 1974 [11,12] We have annually tested 200,000-250, 000 primary and junior high school students, aged 7-15 years, at the screening program. We demonstrated that about $30 \%$ of school students with positive urine glucose was diagnosed as having diabetes, mostly type 2 diabetes, as results of OGTT and HbA1c levels in the detailed examination of the screening program. On the other hand, almost $70 \%$ with glucosuria was finally identified as having RG with no evidence of glucose intolerance in the detailed examination. We found the positive rate for glucosuria in the first urine test of the screening program to be approximately $0.1 \%$, therefore estimated prevalence of $\mathrm{RG}$ in the screening program was approximately $0.07 \%$ [10]. Crombie DL [13] proposed that the prevalence of RG was $0.29 \%$ in the general Caucasian population. Prevalence of RG in Japanese school children seems to be lower than that in the Caucasian population proposed by Crombie DL, which might be due to racial difference of the frequency of RG.

By interviewing from the children's parents in the screening program, about $70 \%$ of cases had second-degree relatives with suspected RG, who showed a normal blood glucose level despite a positive urine glucose, detected by previously performed urine glucose test at school, at a regular medical checkup at their companies, or at a medical checkup during pregnancy, etc. Almost all cases were affected by one parent, either father or mother [10]. In conclusion, we demonstrated approximately $70 \%$ of subjects with urine glucose positive at a screening program at school are identified as having RG. RG may be not rare, but a frequent condition with glucosuria among Japanese school children.

\section{References}

1. Marble A (1932) Renal glucosuria. Am J Med Sci 183: 811-827.

2. Lawrence RD (1947) Symptomeless glucosurias: differentiation by sugar tolerance tests. Med Clin North Am 31(2): 289-297.

\section{ISSN: 2574-1241}

DOI: 10.26717/BJSTR.2018.07.001506

Tatsuhiko Urakami. Biomed J Sci \& Tech Res

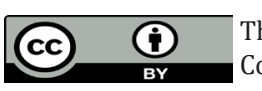

This work is licensed under Creative Commons Attribution 4.0 License

Submission Link: https://biomedres.us/submit-manuscript.php
3. Desjeux JF (1989) Congenital selective $\mathrm{Na}^{+}$, D-glucose cotransport defects leading to renal glucosuria and congenital selective intestinal malabsorption of glucose and galactose. In: Scriver CR, Beadet AL, Sly WS, Valle D (Eds.). The Metabolic Basis of Inherited Disease ( $6^{\text {th }}$ Edn.). McGraw Hill, New York, USA, pp: 2463-2478.

4. Wright EM, Turk E (2004) The sodium/glucose cotransporter family SLC5. Pflugers Arch 447(5): 510-518.

5. Magen D, Sprecher E. Zelikovic I, Skorecki K (2005) A novel missense mutation in SLC5A2 encoding SGLT2 underlies autosomal-recessive renal glucosuria and aminoaciduria. Kidney Int 67(1): 34-41.

6. Santer R, Calado J (2010) Familial renal glucosuria and SGLT2: From a Mendelian trait to a therapeutic target. Clin J Am Soc Nephrol 5(1): 133141.

7. Kanai Y, Lee WS, You G, Brown D, Hediger MA (1994) The human kidney low affinity $\mathrm{Na}+$ /glucose transporter SGLT2: Delineation of the major renal reabsorptive mechanism for D-glucose. J Clin Invest 93(1): 397404.

8. Santer R, Calado J (2010) Familial renal glucosuria and SGLT2: From a Mendelian trait to a therapeutic target. Clin J Am Soc Nephrol 5(1): 133141.

9. Khachadurian AK, Khachadurian LA (1964) The inheritance of renal glycosuria. Am J Hum Genet 16(2): 189-194.

10. Urakami T, Yoda M, Yoshida K, Mine Y, Aoki M, Suzuki J (2017) Clinical characteristics of schoolchildren with renal glucosuria. Pediatr Int 60(1): 189-194.

11. Urakami T, Kubota S, Nitadori Y, Harada K, Owada M, et al. (2005) Annual incidence and clinical characteristics of type 2 diabetes in children as detected by urine glucose screening in the Tokyo metropolitan area. Diabetes Care 28(8): 1876-1881.

12. Urakami T, Morimoto S, Nitadori Y, Harada K, Owada M, et al. (2007) Urine glucose screening program at schools in Japan to detect children with diabetes and its outcome- Incidence and clinical characteristics of childhood type 2 diabetes in Japan. Pediatr Res 61: 141-145.

13. Crombie DL (1962) Incidence of glucosuria and diabetes. Proc R Soc Med 55(3): 205-211.

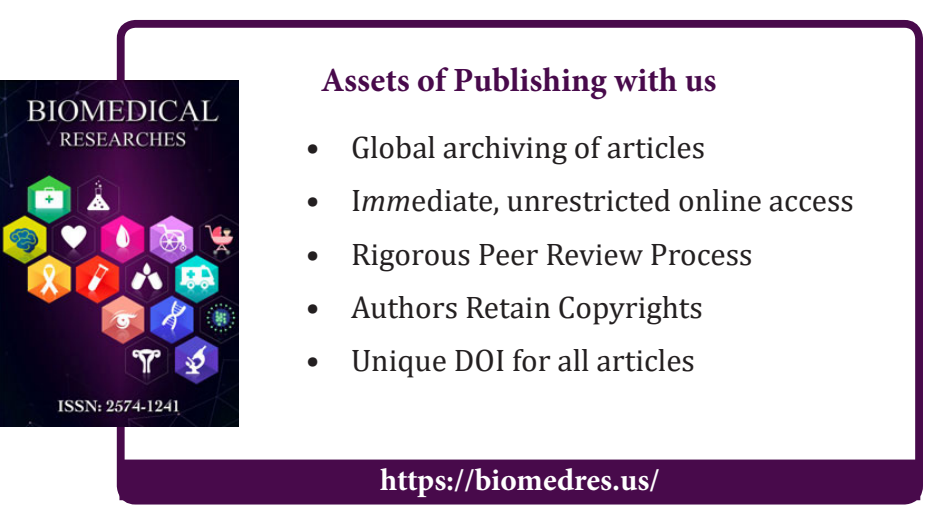

